\title{
The Process Evaluation of a Comparative Controlled Trial to Support Self-management for the Prevention and Management of Type 2 Diabetes in Uganda, South Africa and Sweden in the SMART2D Project.
}

Josefien van Olmen ( $\nabla$ josefien.vanolmen@uantwerpen.be)

Institute of Tropical Medicine https://orcid.org/0000-0001-9724-1887

Pilvikki Absetz

Tampere University

Roy William Mayega

Makerere School of Public Health

Linda Timm

Karolinska Institute

Peter Delobelle

University of Western Cape

Helle Molsted-Alvesson

karolinska Institute

Gloria Naggayi

Makerere School of Public Health

Francis Kasujja

Makerere School of Public Health

Mariam Hassen

University of the Western Cape

Jeroen De Man

University of Antwerp

Kristi Sidney-Annersted

Karolinska Institute

Thandi Puoane

University of Western Cape

Claes-Goran Ostenson

Karolinska Institute

Göran Tomson

Karolinska

David Guwatudde

Makerere School of Public Health 


\section{Meena Daivadanam}

Uppsala University

\section{Research}

Keywords: Type 2 diabetes, Prevention, Self-Management, Peer support, Disadvantaged settings, Reciprocal learning, Process evaluation, Low \& Middle Income countries, Implementation research, Community interventions

DOI: https://doi.org/10.21203/rs.3.rs-581101/v1

License: (c) (i) This work is licensed under a Creative Commons Attribution 4.0 International License. Read Full License 


\section{Abstract}

Background. Type 2 diabetes (T2D) and its complications are increasing rapidly. Support for healthy lifestyle and self-management is paramount, but not adequately implemented in health systems in most countries. Process evaluations facilitate understanding why and how interventions work through analysing the interaction between intervention theory, implementation and context. The SMART2D project implemented and evaluated community-based support interventions for persons at high risk of or having T2D in a rural community in Uganda, an urban township in South Africa, and socio-economically disadvantaged urban communities in Sweden. This study presents comprehensive analyses of the implementation process and interaction with context.

Methods. This paper reports implementation process outcomes across the three sites, guided by the MRC framework for complex intervention process evaluations and focusing on the three community strategies (peer support program; care companion; and link between facility care and community support). Data were collected through observations of peer support group meetings using a structured guide, and semistructured interviews with project managers, implementers and participants.

Results. The countries focused their in-depth implementation in accordance with the feasibility and relevance in the context. In Uganda and Sweden, the implementation focused on the peer support intervention whereas in South Africa, it centred around the CC part. The community-facility link received the least attention in the implementation. Continuous capacity building received a lot of attention, but intervention reach, dose delivered and fidelity varied substantially. Intervention- and context-related barriers affected participation. The analysis revealed how context shaped the possibilities of implementation, the delivery and participation and affected the mechanism of impact.

Conclusions. Identification of the key uncertainties and conditions facilitates focus and efficient use of resources in process evaluations, and context relevant findings. The use of an overarching framework allows to collect cross-contextual evidence and a flexibility in evaluation design to adapt to the complex nature of the intervention. When designing an intervention, it is crucial to consider aspects of the implementing organization or structure, absorptive capacity, and to thoroughly assess and discuss implementation feasibility, capacity and organizational context with the implementation team and recipients. These recommendations are important for implementation and scale up.

Trial registration. ISRCTN 11913581 (Registration 1/10/2017, https://doi.org/10.1186/ISRCTN11913581)

\section{Contributions To The Literature}

- Process evaluations facilitate understanding why and how interventions work through analysing the interaction between theory, implementation and context. To efficiently use resources, process evaluations ideally focus on the most relevant uncertainties. This focus is often not made explicit. 
- This study identified key uncertainties and context-specific questions for implementation in an overarching framework. Countries focused their in-depth implementation in accordance with feasibility and relevance in the context.

- Our findings suggest the following key elements for designing an intervention: aspects of the implementing organization or structure, absorptive capacity, implementation feasibility, capacity and organizational context of the implementation team and or the recipients.

\section{Background}

Non-Communicable Diseases (NCDs) such as type 2 diabetes (T2D) comprise the largest global burden of disease [1]. While efficacious interventions to prevent and control NCDs exist, contextualised largescale implementation is lagging behind. Results of existing implementation studies vary [2] and negative findings seem to be linked with challenges in design and implementation [3]. By analyzing the interaction between intervention theory, implementation and context, process evaluations facilitate in understanding why and how interventions work and how they can be strengthened for improved effectiveness, dissemination or scale-up to other population groups and settings [4].

The 'Self-Management and Reciprocal learning for Type 2 Diabetes' (SMART2D) project implemented a self-management support intervention for T2D in three different settings: a rural community in Uganda (low-income country), a semi-urban township in Cape Town, South Africa (middle-income country), and socioeconomically disadvantaged suburbs with a high proportion of immigrants in Stockholm, Sweden (high-income country). The aim of the project was to formulate and implement contextually appropriate self-management strategies for the prevention and control of T2D in each setting and to evaluate its outcomes [5]. The SMART2D intervention, developed in a collaborative process with research teams and stakeholders in the participating countries [6], resulted in an complex intervention design with shared key functions but - for ensuring cultural fit in each setting - had contextualized content and delivery which operated on multiple levels [7]. The intervention development took into account contextual weaknesses and strengths with regards to self-management support, identified through interviews with local stakeholders (local governments, community organisations, outreach workers, individuals with, or at high risk of T2D, and healthcare providers) [8].

To efficiently use resources, process evaluations ideally focus on the most relevant uncertainties related to implementation in the context [9]. This focus is often not made explicit by designers, implementers and researchers, which affects the quality and utility of such evaluations [10]. The reciprocal learning approach in SMART2D [11] enabled the research team to identify uncertainties and operational research questions for each country context, within an overarching evaluation framework. This was the Medical Research Council (MRC) guidance for process evaluations [4] because it allows a comprehensive assessment of the implementation of complex interventions, taking into account the delivery, participation and context. This paper presents a comprehensive analyses of the SMART2D implementation process and of the interaction with context. The paper aims to contribute to an understanding of trial results. 


\section{Methods}

\section{Aim, design and study setting of the SMART2D intervention}

The intervention package consisted of facility and community strategies [7], [12]. The trial had two arms: a facility care only arm and an integrated care arm with combined facility and community strategies. The main aim of the facility strategies was to standardize a minimum level of care across the two study arms. This paper focuses on the community strategies of the integrated care arm that are deemed most important for transfer and scale-up, evaluated through an adaptive implementation trial in Uganda and South Africa and a feasibility trial in Sweden: a) community mobilisation; b) peer support programme; c) Care Companion (CC); and d) community extension, linking the community and facility [7]. Implementation of the intervention was conducted during nine months in Uganda and South Africa, and 13 weeks in Sweden. The follow-up duration of participants was 12 months Uganda 9 months in South Africa and three months in Sweden [5]. The deviation from the protocol in Sweden was related to major changes in intervention delivery after a pilot study had shown poor acceptability of the group-based peer support program which led to an individual telephone-facilitated health coaching program [7].

The assumptions underlying the intervention and mechanisms of impact originated in the transdisciplinary conceptual framework developed for this project based on the Self-Determination theory (SDT) [8]. The peer support facilitators operating face-to-face peer groups (Uganda and South Africa) or tele-health coaching sessions (Sweden) were trained to use person-centred techniques from motivational behavioural coaching to foster participants' need for autonomy, relatedness, and competence in making lifestyle changes. Based on the SDT framework, satisfaction of these needs was hypothesized to lead to increased autonomous motivation, in turn resulting in more sustained behaviour change [13]. The CC intervention, delivered by a significant other or someone in their social network, was assumed to contribute to perceived relatedness through emotional, practical, and ongoing support of study participants. The community-facility link was hypothesized to ensure the flow of information, feedback, and support between community and facility. Implementation of the community extension was achieved through study participant peer group leaders and nurses in Uganda, expanding the role of Community Health Workers (CHWs) in South Africa, and inspiration meetings bringing together participants and community and facility actors in Sweden.

The SMART2 intervention is a complex intervention, because of its multiple interacting components, the narrow interaction between local context and implementation [14]. Implications were that a close collaboration between the research and local implementation teams for delivery of intervention, organisational and logistical challenges to ensure adequate research design and delivery of active ingredients of the intervention, coping with changes in local health service organisation or policies, such as the reorganisation of health districts or transfer of staff. These changes meant continuous reassessment of barriers and uncertainties, which asked for a flexible evaluation framework allowing researchers to go back and forth in the sequence of data collection and analysis and to have repetitive interactions with implementors and local stakeholders. This resulted in the joint determination of joint 
targets for process and outcomes of the implementation strategy, established in a joint implementation evaluation framework

\section{Evaluation framework and measures of the implementation strategy}

Evaluation was based on the MRC guidance [4] and the taxonomy of implementation outcomes [15], allowing us to structure the evaluation into three parts: 1) components of the intervention and interaction with context; 2) implementation; and 3) mechanism of impact (participant level) (Fig. 1). Evaluation components for the implementation outcomes included: Capacity building being training and supervision; Reach being the proportion of the target population reached by the intervention; Dose delivered being the quantity of the intervention (measurable only for $b$, the target being participants having received at least $1 / 3$ of all sessions); Fidelity being implementation according to protocol; and Adaptations to the implementation protocol. The evaluation components for mechanisms of impact were: Participation of study subjects in activities; Mediators defined as the interaction of participants with the intervention; and barriers and facilitators. Participation and Mediators were not relevant for strategy $d$, since this was not targeting the study participants. Since component a was primarily meant to boost participation to the core components $b$-d, this component was only assessed for reach and participation. The context factors are relevant to all elements and are therefore placed on top in the figure. They include the health facility which participants attended and influences from the wider environment. Measures used for the evaluation of these elements are described in Table 1. 
Table 1

Data collection table (horizontal sequence Fig. 1 transposed to a vertical sequence). $C=$ Capacity Building; $\mathrm{R}=$ Reach; $\mathrm{D}=$ Dose delivered $\mathrm{F}=$ Fidelity; $\mathrm{A}=$ Adaptations; $\mathrm{P}=$ Participation; $\mathrm{M}=$ Mediators

$\begin{array}{llll}\text { MRC } & \text { Adaptation to } & \text { Operationalisation into topics \& } \\ \text { concepts } & \begin{array}{l}\text { SMART2D } \\ \text { intervention }\end{array} & \text { measures } & \begin{array}{l}\text { Source of data \& data } \\ \text { collection tools }\end{array}\end{array}$

Context

$\begin{array}{lll}\text { Health facility } & \begin{array}{l}\text { Routine care; interaction with } \\ \text { research project }\end{array} & \text { Project manager } \\ \text { Environment } & \begin{array}{l}\text { Presence of health comm'y } \\ \text { organisations; comm'y ties; physical } \\ \text { environment }\end{array}\end{array}$

Community mobilisation

Implementation

R Reach $\begin{aligned} & \text { Settings in which recruitment was Consortium reports } \\ & \text { done }\end{aligned}$

Duration of recruitment

A Adaptations Problems and adaptations

Participation

$\begin{array}{lll}\text { P Participation } & \text { Number (No) of people screened } & \begin{array}{l}\text { Site reports; monthly } \\ \text { consortium meetings }\end{array} \\ \text { No of people enrolled } & \begin{array}{l}\text { Problems experienced by potential } \\ \text { participants }\end{array}\end{array}$

a Peer support program

Implementation

$\begin{array}{lll}\text { C Capacity building } & \text { No of peer leaders/facilitators trained } & \begin{array}{l}\text { Project manager, } \\ \text { consortium reports }\end{array} \\ & \text { No of initial trainings } & \text { No of refresher trainings } \\ & \begin{array}{l}\text { Other supervision/monitoring } \\ \text { activities }\end{array}\end{array}$
R \% target audience in contact with interventions No of invitations sent to participate in
peer support sessions
Project manager, consortium reports

No of peer groups established: group size (median, range) 


\section{MRC Adaptation to \\ concepts SMART2D \\ Operationalisation into topics \& \\ intervention \\ measures

D Nr of sessions delivered

F $\quad$ Fidelity with protocol
No of meetings / group: median, range

No of groups covering all manual

topics

Topics not (or hardly) covered

Checklist/Facilitator: 2Q (U) / 7Q (SA) Webannex 2a-2b-2c / 10 Q (SW)
A Adaptations
Problems \& adaptations
Facilitators

Mechanisms of Impact /

Participation

P $\quad \begin{aligned} & \text { Responses to } \\ & \text { intervention }\end{aligned}$
inten

Participation: median level received

Participation: min level received

M Interaction with facilitator

B/F Barriers/facilitators
No of people that attended at least 1 session

No of individual contacts/participant
Peer support reports

No of people having attended $1 / 3$ of total sessions

Checklist/participation: 2Q (U)/ 3Q (SA)/ 4Q (SW)

Problems experienced by participants
Webannex 2a-2b-2c

Participant interviews and project managers

\section{b Care Companion (CC)}

Implementation

\begin{tabular}{llll}
$\mathbf{C}$ & Capacity building & $\begin{array}{l}\text { Development and distribution of CC } \\
\text { guide }\end{array}$ & Webannex 3 \\
\hline $\mathbf{R}$ & $\begin{array}{l}\text { \% target audience } \\
\text { reached by the } \\
\text { intervention }\end{array}$ & $\begin{array}{l}\text { No of participants being offered the } \\
\text { option of CC }\end{array}$ & $\begin{array}{l}\text { Project manager, } \\
\text { consortium reports }\end{array}$ \\
$\mathbf{F}$ & $\begin{array}{l}\text { Fidelity with CC } \\
\text { guidelines }\end{array}$ & Explanation of 6 CC tasks to CC &
\end{tabular}

Systematic invitation to clinic visits and peer support
A Adaptations
Problems and adaptations

Mechanisms of Impact /

Participation 


\begin{tabular}{|c|c|c|c|}
\hline $\begin{array}{l}\text { MRC } \\
\text { concepts }\end{array}$ & $\begin{array}{l}\text { Adaptation to } \\
\text { SMART2D } \\
\text { intervention }\end{array}$ & $\begin{array}{l}\text { Operationalisation into topics \& } \\
\text { measures }\end{array}$ & $\begin{array}{l}\text { Source of data \& data } \\
\text { collection tools }\end{array}$ \\
\hline $\mathbf{P}$ & Identification CC & $\begin{array}{l}\text { No of people having a CC/engaging } \\
\text { with a CC }\end{array}$ & \multirow{2}{*}{$\begin{array}{l}\text { Peer support reports, } \\
\text { Care Companion } \\
\text { checklist (SA) }\end{array}$} \\
\hline \multirow[t]{3}{*}{ M } & $\begin{array}{l}\text { Engagement CC in } \\
\text { the } 6 \text { tasks }\end{array}$ & $\begin{array}{l}\text { Reminding/Participation in clinic } \\
\text { visits and/or peer support } \\
\text { programme (taks } 1,4)\end{array}$ & \\
\hline & & $\begin{array}{l}\text { Reminders to participants on } \\
\text { medicaiton and monitoring (taks } 2,3 \text { ) }\end{array}$ & \multirow{3}{*}{$\begin{array}{l}\text { Interviews CC, } \\
\text { participants, and } \\
\text { progamme managers }\end{array}$} \\
\hline & & $\begin{array}{l}\text { Supporting physical activity and } \\
\text { healthy diet (tasks } 5,6 \text { ) }\end{array}$ & \\
\hline \multicolumn{2}{|l|}{$B / F$} & Problems experienced by peers & \\
\hline \multicolumn{3}{|c|}{ Community-facility link } & \\
\hline \multicolumn{4}{|c|}{ Implementation } \\
\hline C & $\begin{array}{l}\text { Capacity building: } \\
\text { training }\end{array}$ & $\begin{array}{l}\text { Explanation/discussion about } \\
\text { expectations }\end{array}$ & \multirow[t]{5}{*}{$\begin{array}{l}\text { Project manager, } \\
\text { consortium reports }\end{array}$} \\
\hline D & $\begin{array}{l}\text { Implementation: } \\
\text { dose delivered }\end{array}$ & $\begin{array}{l}\text { No community actors in contact with } \\
\text { facility actors }\end{array}$ & \\
\hline $\mathbf{F}$ & & Introduction between actors & \\
\hline \multicolumn{3}{|c|}{$\begin{array}{l}\text { Mechanisms of Impact / } \\
\text { Participation }\end{array}$} & \\
\hline$B / F$ & Barriers/facilitators & & \\
\hline
\end{tabular}

\section{Measures and data collection}

Measures were developed for the evaluation of the implementation and the mechanisms of impact, for each of the four intervention components. Table 1 provides the adaptation of the MRC taxonomy to the intervention components and for the context, and measures and sources of data collection. Primary data were collected in each country using structured and informal observations of field visits by project management staff, interviews with implementers and participants, project documents including participant attendance lists, country reports (which in Sweden were based upon a REDCAP continuous intervention tracking tool) and monthly SMART2D consortium meetings. Structured process evaluation tools included: interaction checklists contextualized into a peer group checklist (Webannex 2a, Uganda), a quality assurance checklist (Webannex $2 b$, South Africa); a quality assurance/interaction tool (Webannex 2c, Sweden); and a care companion checklist (Webannex 3). 
During the development and early implementation stages, research team observations led to the identification of context-specific questions for implementation. Countries developed additional process evaluation measures to answer these context-specific questions: Uganda evaluated the facility intervention component (facility checklist, Webannex 1) and compiled an overall process evaluation report [16] ; South Africa assessed capacity building of the implementing organization; and Sweden assessed the recruitment, reach and acceptability of the intervention and on the interaction between facilitators and participants [17]. These data were reported separately but also provided more in-depth understanding of the cross-country evaluation. Each of the three country implementation managers (LT, $\mathrm{FK}, \mathrm{MH}$ ) filled in the cross-country data collection table based on the primary data. This was further discussed and clarified within country teams and in two cross-country meetings.

\section{Results}

Table 2 gives an overview of the process evaluation results for context, community mobilisation and the three intervention components as implemented at the three sites. 
Table 2

Results of process evaluation - part II. Denominator is number of people enrolled in community intervention (See Table 2). C = Capacity Building; R = Reach; D = Dose delivered; F = Fidelity; A = Adaptation; $\mathrm{P}=$ Participation; $\mathrm{M}=$ Mediators; $\mathrm{Q}=$ Question; comm'y = community

$\begin{array}{lllll}\begin{array}{l}\text { MRC } \\ \text { concept }\end{array} & \text { Measures } & \text { Uganda } & \text { South Africa } & \text { Sweden }\end{array}$

Context

Health facility: routine
care; interaction with
research project

Health facility: routine research project routine care was

strengthened;

strong

interaction with

research project

strengthened

through pre-

existing

collaboration

with the research

site

\begin{abstract}
Environment: presence of health comm'y organisations; comm'y ties; physical environment
\end{abstract}

no health comm'y organisations; strong comm'y ties; rural area long travel distances routine care as usual; little interaction with research project but more interest from staff in the control site routine care as usual; interaction with research team interrupted due to change of site presence of NGO with $\mathrm{CHW}$; frequent migration hinders strong community ties; urban very disadvantaged neighbourhood, perceived safety concerns diabetes NGO not reaching the target population; community ties weak,social gatherings often religious/socially inspired; urban disadvantaged areas

SMART2D Research team

\begin{tabular}{|c|c|}
\hline $\begin{array}{l}\text { Organisational context: } \\
\text { daily management }\end{array}$ & $\begin{array}{l}\text { Peer groups, } \\
\text { supported by } \\
\text { research field } \\
\text { manager }\end{array}$ \\
\hline
\end{tabular}

a. Community mobilisation \& Recruitment

Implementation

R Recruitment setttings

Duration (months)

A
Problems and adaptations

Community house to house visits 11

large team of field assistants; need for strict quality control screening
Facility chronic care clinics

18

changed of site delayed familiarisation; university turmoil delayed team work; community sensitisation event
Community public spaces; facility registers

\section{8}

chang of site; 2step screening led to loss in recruitment, adaptation to 1step \& inclusion changed to highrisk 


\begin{tabular}{|c|c|c|c|c|}
\hline $\begin{array}{l}\text { MRC } \\
\text { concept }\end{array}$ & Measures & Uganda & South Africa & Sweden \\
\hline \multirow[t]{3}{*}{$\mathbf{P}$} & $\begin{array}{l}\text { Total number of people } \\
\text { screened }\end{array}$ & 28976 & 2150 & 1965 \\
\hline & $\begin{array}{l}\text { Number of people } \\
\text { enrolled in community } \\
\text { intervention }\end{array}$ & 268 & 285 & 131 \\
\hline & $\begin{array}{l}\text { Problems experienced } \\
\text { by potential participants }\end{array}$ & $\begin{array}{l}\text { enrolment at } \\
\text { facility implied } \\
\text { travel and } \\
\text { waiting }\end{array}$ & $\begin{array}{l}\text { high mobility } \\
\text { linked to circular } \\
\text { migration } \\
\text { decreased long- } \\
\text { term participation }\end{array}$ & language barriers \\
\hline
\end{tabular}

b Peer support program

Implementation

C No of peer

leaders/facilitators

trained

19

10

6

No of initial + refresher $\quad 4+2$

trainings

Other supervision /

monitoring support

activities

2 supervision
visits / group

\begin{tabular}{l} 
R $\quad \begin{array}{l}\text { No of invitations to } \\
\text { participants for peer } \\
\text { support sessions }\end{array}$ \\
\hline
\end{tabular}

No of peer groups 19 groups: size

established \& group size $10(4-27)$

(median, range)

D No of meetings / group: 10 (NA)

median (range)

F No of groups covering

all manual topics

Topics not / hardly covered

17

none

3 groups: size 15

(10-20)

weekly common

mock sessions \&

quality assurance

visit

375

$2(1-2)$

$3,5(1-9)$

49

alcohol \& drug

risks; community

walk

community walk;

goal-setting

care companion

activities

Overall score 7 out of 10

median score 4 out of 5 (IQR 4-5) on leadership/content median score 81 out of 100 (IQR 76-94) on delivery: 75 (7078) on interest 


\begin{tabular}{|c|c|c|c|c|}
\hline $\begin{array}{l}\text { MRC } \\
\text { concept }\end{array}$ & Measures & Uganda & South Africa & Sweden \\
\hline \multirow[t]{3}{*}{ A } & Problems & $\begin{array}{l}\text { manual too } \\
\text { difficult; } \\
\text { language not } \\
\text { adapted }\end{array}$ & $\begin{array}{l}\text { management } \\
\text { problems at } \\
\text { implementing } \\
\text { organisation: slow } \\
\text { skill-building, } \\
\text { manual not } \\
\text { followed, poor } \\
\text { record keeping, } \\
\text { locations small }\end{array}$ & $\begin{array}{l}\text { participants hard } \\
\text { to reach, several } \\
\text { phone calls } \\
\text { needed }\end{array}$ \\
\hline & Adaptations & $\begin{array}{l}\text { retranslated, } \\
\text { mock sessions }\end{array}$ & $\begin{array}{l}\text { more time, mock } \\
\text { sessions; } \\
\text { experienced peer } \\
\text { facilitators to } \\
\text { support }\end{array}$ & $\begin{array}{l}\text { individual } \\
\text { coaching } \\
\text { sessions }\end{array}$ \\
\hline & & & $\begin{array}{l}\text { testing opportunity } \\
\text { increased } \\
\text { attendance }\end{array}$ & $\begin{array}{l}\text { facilitator } \\
\text { switches for } \\
\text { language }\end{array}$ \\
\hline \multicolumn{5}{|c|}{ Mechanisms of Impact / participation } \\
\hline \multirow[t]{2}{*}{$\mathbf{P}$} & $\begin{array}{l}\text { No of people that } \\
\text { attended at least } 1 \\
\text { session }\end{array}$ & $100 \%$ & $61 / 285 \sim 21 \%$ & $72 / 131 \sim 55 \%$ \\
\hline & $\begin{array}{l}\text { No of people that } \\
\text { attended } 1 / 3 \text { of total } \\
\text { sessions }\end{array}$ & $76 / 268 \sim 28 \%$ & $53 / 285 \sim 19 \%$ & $49 / 131 \sim 37 \%$ \\
\hline M & $\begin{array}{l}\text { Interaction with } \\
\text { facilitator }\end{array}$ & $\begin{array}{l}\text { good: average } \\
\text { score } 7 \text { out of } 10\end{array}$ & $\begin{array}{l}\text { median score } 4 \text { out } \\
\text { of } 5 \text { (IQR 4-5) on } \\
\text { participation }\end{array}$ & $\begin{array}{l}\text { good: median } 75 \\
\text { out of } 100 \text { (IQR } \\
69-81 \text { ) on } \\
\text { engagement }\end{array}$ \\
\hline$B / F$ & $\begin{array}{l}\text { Problems experienced } \\
\text { by participants }\end{array}$ & $\begin{array}{l}\text { timing sessions } \\
\text { interferes with } \\
\text { work, especially } \\
\text { in agricultural } \\
\text { season }\end{array}$ & $\begin{array}{l}\text { timing, safety, } \\
\text { wheater, } \\
\text { migration/informal } \\
\text { settling, change of } \\
\text { cell phone, other } \\
\text { duties }\end{array}$ & $\begin{array}{l}\text { no time; language; } \\
\text { variability in pre-- } \\
\text { knowledge }\end{array}$ \\
\hline \multicolumn{5}{|c|}{ Care Companion (CC) } \\
\hline \multicolumn{5}{|c|}{ Implementation } \\
\hline C & CC guide & brochure & $\begin{array}{l}\text { information to } \\
\text { CHW, not to } \\
\text { patients }\end{array}$ & $\begin{array}{l}\text { oral information } \\
\text { and brochure }\end{array}$ \\
\hline $\mathbf{R}$ & $\begin{array}{l}\text { No of people being } \\
\text { offered the option of CC }\end{array}$ & $268 / 268 \sim 100 \%$ & $208 / 285 \sim 73 \%$ & $72 / 131 \sim 55 \%$ \\
\hline $\mathbf{F}$ & $\begin{array}{l}\text { Explanation of } 6 \mathrm{CC} \\
\text { tasks to CC }\end{array}$ & $\begin{array}{l}\text { by nurse at } \\
\text { health center }\end{array}$ & partly & $\begin{array}{l}\text { by facilitator and } \\
\text { at sessions }\end{array}$ \\
\hline
\end{tabular}




\begin{tabular}{|c|c|c|c|c|}
\hline \multirow{2}{*}{$\begin{array}{l}\text { MRC } \\
\text { concept }\end{array}$} & Measures & Uganda & South Africa & Sweden \\
\hline & $\begin{array}{l}\text { Systematic invitation to } \\
\text { clinic visits and peer } \\
\text { support }\end{array}$ & Yes & Yes & Yes \\
\hline \multirow[t]{2}{*}{ A } & $\begin{array}{l}\text { Problems and } \\
\text { adaptations }\end{array}$ & $\begin{array}{l}\text { failure to identify } \\
\text { CC }\end{array}$ & $\begin{array}{l}\text { patients did not } \\
\text { identify a peer; } \\
\text { CHW became CC; } \\
\text { little knowledge } \\
\text { transfer }\end{array}$ & $\begin{array}{l}\text { patients did not } \\
\text { want/peers did } \\
\text { not want }\end{array}$ \\
\hline & & encouragement & $\begin{array}{l}\text { re-train \& prep } \\
\text { sessions on } \\
\text { expectations }\end{array}$ & $\begin{array}{l}\text { pairing } \\
\text { participants; } \\
\text { multiple peers }\end{array}$ \\
\hline \multicolumn{5}{|c|}{ Mechanisms of change / Participation } \\
\hline $\mathbf{P}$ & $\begin{array}{l}\text { No of people having a } \\
\text { CC }\end{array}$ & $\begin{array}{l}268 / 268 \sim 100 \% \\
\text { (on paper) }\end{array}$ & $\begin{array}{l}\text { CC performing at } \\
\text { least } 1 / 3 \text { of agreed } \\
\text { (home) visits: } \\
185 / 285 \sim 65 \%\end{array}$ & $43 / 131 \sim 33 \%$ \\
\hline \multirow[t]{3}{*}{ M } & $\begin{array}{l}\text { Reminding/Participation } \\
\text { in clinic visits and/or } \\
\text { peer support } \\
\text { programme }\end{array}$ & $\begin{array}{l}\text { CC attendance of } \\
\text { community } \\
\text { activities } \\
(42 / 268 \sim 16 \%)\end{array}$ & Yes & $\begin{array}{l}\text { some joint } \\
\text { actitivies }\end{array}$ \\
\hline & $\begin{array}{l}\text { Reminders to } \\
\text { participants on } \\
\text { medication and } \\
\text { monitoring }\end{array}$ & $\begin{array}{l}\text { Active CC } \\
\text { (roughly 50\%) } \\
\text { provided } \\
\text { medication } \\
\text { reminders }\end{array}$ & Yes & Not done \\
\hline & $\begin{array}{l}\text { Supporting physical } \\
\text { activity and healthy diet }\end{array}$ & $\begin{array}{l}\text { Active CC } \\
\text { (roughly } 50 \% \text { ) } \\
\text { reminders, } \\
\text { sometimes } \\
\text { support in } \\
\text { cooking }\end{array}$ & $\begin{array}{l}\text { Focus on setting } \\
\text { goals }\end{array}$ & $\begin{array}{l}\text { Limited attempts } \\
\text { for joint activities }\end{array}$ \\
\hline$B / F$ & Problems by peers & $\begin{array}{l}\text { Many elderly, } \\
\text { living alone }\end{array}$ & & $\begin{array}{l}\text { People could } \\
\text { not/did not want }\end{array}$ \\
\hline \multicolumn{5}{|c|}{ Community-facility link } \\
\hline \multicolumn{5}{|c|}{ Implementation } \\
\hline C & $\begin{array}{l}\text { Explanation } \\
\text { expectations }\end{array}$ & Yes & No & $\begin{array}{l}\text { training meetings } \\
\text { in behaviour } \\
\text { coaching }\end{array}$ \\
\hline D & $\begin{array}{l}\text { No community actors in } \\
\text { contact with facility } \\
\text { actors }\end{array}$ & $\begin{array}{l}\text { 17: materials and } \\
\text { feedback } \\
\text { reciprocal }\end{array}$ & $\begin{array}{l}\text { Informal: not } \\
\text { linked to } \\
\text { community } \\
\text { intervention }\end{array}$ & $\begin{array}{l}2 \text { meetings for all } \\
\text { actors: } \\
\text { facilitators, health } \\
\text { workers, patients } \\
\text { and experts }\end{array}$ \\
\hline
\end{tabular}




\begin{tabular}{|cllll|}
\hline $\begin{array}{l}\text { MRC } \\
\text { concept }\end{array}$ & Measures & Uganda & South Africa & Sweden \\
\hline F & Intro between actors & Yes & $\begin{array}{l}\text { Not in a structured } \\
\text { way }\end{array}$ & Yes \\
\hline Mechanisms of Impact / Participation & & \\
\hline B/F & Barriers/facilitators & $\begin{array}{l}\text { CHW contact with } \\
\text { health workers not } \\
\text { structural, } \\
\text { relationship } \\
\text { perceived as } \\
\text { unequal by CHW }\end{array}$ & $\begin{array}{l}\text { low interest in the } \\
\text { other side of the } \\
\text { link, little time } \\
\text { investment done }\end{array}$ \\
\hline
\end{tabular}

\section{Context and the influence on the intervention}

The wider societal and policy context influenced the implementation in all three countries. In South Africa, the national policy on CHW activities changed during the project, which led to a change in geographical catchment areas and incentive systems. The facility context provided routine care and prevention in the community intervention. In South Africa and Sweden, facility staff were informed about the community intervention, but diabetes care went on as usual. In Uganda, to guarantee at least the minimum level of quality care for all participants, facility care was upgraded with participants in all study arms receiving adequate medications and staff in the active intervention arms receiving training in diabetes health education.

Environmental factors influenced the different options for intervention delivery. The choice to involve an existing service organisation in South Africa was rooted in the health system tradition of using CHWs. This facilitated the delivery process because it engaged an existing cadre of local health workers that was familiar to participants. CHWs took up a modified role as CC and focused more on behaviour change support. The organisational context, including weak management and high staff turnover, however, affected the perceived support of CHWs. The physical environment in Uganda was rural, and peer support was organised around parish communities, where existing social capital leveraged group development. The urban environments in South Africa and Stockholm proved to be contexts with less social cohesion or community ties. In South Africa, safety issues threatened intervention and participation. In Sweden, participants were often constrained by economic hardship, language barriers and feelings of isolation, but the peer support intervention provided an opportunity to build valued relationships of trust. The research partner was also a trusted partner in all three country contexts.

\section{Community mobilization}

Mobilization strategies were primarily used to boost participant recruitment and included information campaigns through brochures, posters and local information channels covering issues about lifestyle, diabetes, screening and health care services in the study area. Strategies were community-based in 
Uganda, facility-based in South Africa and a mix of both in Sweden [18] and lasted 11 months in Uganda and 18 months each in Sweden and South Africa. In Uganda 28,976 households were visited for screening and 268 participants were enrolled in the community intervention arm (142 people with T2D and 126 people at high risk). In South Africa, 2,150 people were screened as eligible and 285 participants were enrolled in the community intervention arm (140 T2D and 145 persons at risk of T2D). In Sweden, 1,965 people were screened in the communities [19] and T2D patients were recruited through registers at primary health care centres, enrolling 131 participants in the community intervention arm (51 with T2D and 80 at high risk). A common recruitment barrier was the no-show of potential participants for the Fasting Plasma Glucose (FPG) test after the first contact was made, especially for the community-based screening. In Uganda, the need to do a facility based third test meant travel and waiting time for participants. In South Africa, the high mobility, frequent change of cell phone numbers and lack of perceived interest led to high attrition rates after the recruitment phase. Similarly, in Sweden, it proved challenging to commit participants to a research project over an extended period of time.

\section{Peer support program}

Implementation. In Uganda, peer group leaders were fellow patients identified from each group and trained as facilitators; hence the number of facilitators was larger (19) than in the other two settings. In South Africa, the project partnered with a Non-Governmental Organisation (NGO) which conducted community health work and trained ten $\mathrm{CHWs}$ as facilitators. In Sweden, six research assistants were trained as peer supporters / facilitators. Although the profile of facilitators was different in each country, similar needs were observed to ascertain fidelity: refresher trainings and mock sessions were organised to build capacity in motivational coaching and group facilitation. In each country, facilitators strived to maintain contact with participants throughout the intervention. In Uganda, 19 peer groups were established and a median of 10 sessions were organised per peer group. Study participant groups were able to self-organise and adapt place and time to their needs. In South Africa, only three groups were established covering roughly 75 participants with a varying composition including non-study participants. The groups convened once or twice, organised and facilitated by the NGO leading the intervention. Facilitators in Sweden established 72 peer-facilitator dyads with a median of 3,5 sessions per participant, and an average of six phone call attempts before contact could be established. Intervention fidelity in Uganda was assessed through a combined fidelity/participation score (averaging 7 out of 10) [16]. In South Africa, only five sessions were scored for fidelity, with initial sessions scoring very low, but later sessions improving. Qualitative reports and observations revealed that the group discussions focused on acute concerns of participants, rather than following the structure of the manual. Individual goal setting was difficult but the recapturing at follow-up meetings facilitated new reflection. Sweden showed a high intervention fidelity, measured on two axes.

Mechanism of impact. Participants were considered to have received a minimum dose of intervention if they attended one third of the sessions, which included 76 people (28\%) in Uganda, 53 people (19\%) in South Africa and 49 (28\%) in Sweden. Consistent attendance was a major challenge in all countries, due to the timing of sessions, perceived lack of time, and other barriers such as transport costs, weather, and 
migration. The possibility of glucose testing was an additional incentive for attending in South Africa and Uganda. In Uganda, participants appreciated sharing experiences, the peer motivation and follow-up of medical appointments. Diet was the topic most favoured in discussions. Perceived need for participation was affected by variation in pre-existing knowledge, background, and stage of disease, with the highest interest among people diagnosed with T2D. Group leadership was a crucial variable explaining variability among peer group attendance [16]. In South Africa, participants engaged in group discussions, especially in the smaller groups. In Sweden, peer support was highly valued by those who completed the program, and the rapport developed with facilitators appreciated. However, as a side effect of the strong rapport, participants did not seem to perceive active CCs as an important component. Some facilitators were active in suggesting goals, but others also encouraged participants to find a CC and set up goals together.

\section{Care Companion}

Implementation. The CC component was introduced to participants at facility level in Uganda and by telephone facilitated health coaching facilitators in Sweden. Most participants identified a spouse, other household members, or a close neighbour as their CC, as they experienced difficulties to identify other persons or were hesitant to ask. In Sweden, the intervention team adapted by expanding options, for instance pairing participants during facility-community link meetings and suggesting multiple CCs for different activities. In South Africa, early recognition of barriers for identifying a CC in a population with a lot of circular migration [20] led to an adapted model of CHWs acting as CC.

Mechanism of impact. In Uganda, 269 participants (100\%) reported to have a CC, in South Africa 208 out of $285(73 \%)$, and in Sweden $61 \%$. Active involvement of CCs was hindered by time and resource constraints and a lack of perceived relevance, especially when patients were considered stable, as shown in the following quote from a CC: "The battle is not for care companions; it is for the people (who are) affected" [16]. In Sweden, some participants related to the individualistic culture of the context, which made it difficult to seek support. Upon encouragement by the peer support facilitator, some did find a CC. A joint attendance at the inspiration meetings (community extension) could be a joint activity or sometimes establish a CC relationship. CCs were positive about the new knowledge gained at these meetings. However, the participants did not report on specific roles or support of their $\mathrm{CC}$ to achieve their self-management goals. In Uganda, patients reported that the key roles of CCs were to support them in doing physical activity, eating healthy and taking their medication. In South Africa, interviews with CHWs revealed that they felt insufficiently prepared for their new role as $\mathrm{CC}$. While they received immediate feedback in the training sessions for the (group-based) peer support sessions, they lacked training and on the job supervision on how to apply behavior coaching during the household visits. They perceived the new roles to be part of the research project; not a part of their formal job description. They also reported that their CHW uniforms contributed to pre-fixed expectations from people.

\section{Community extension}


Implementation. This aimed at strengthening the link between the community-based intervention and health facility actors. In Uganda and Sweden, introduction meetings between peer support program facilitators and health care staff were organized. In Uganda, regular contact was established through exchange of self-management material and sharing information around defaulters. Although community actors reported a general lack of time and interest from health care staff towards their activities, they experienced synergy from facility activities as health education given by nurses encouraged attendance to the peer support program and reinforced peer program information. In South Africa, the link between facility and community was presumed pre-established through $\mathrm{CHWs}$ who delivered medication during home visits, and no additional actions were organized. The project team observed that the hierarchical facility context and HCW attitudes towards the tasks of CHWs were negative, which hindered a crossfertilization between community and facility support. In Sweden, four neighbourhood meetings were organized for participants and CCs, joined by health care givers, diabetes experts, and community actors, focusing on information exchange and establishing relationships. These were well received.

\section{Discussion}

The analysis of the implementation process of a community T2D prevention and self-management support intervention revealed how the context shaped implementation delivery and participation in three different contexts. Three key findings on implementation emerged from this study. First, comprehensive in-depth implementation of all the intervention elements as planned did not occur. Countries instead focused in-depth implementation on specific elements based on context related conditions and deemed relevance. Second, continuous capacity building received a lot of attention across settings, but intervention reach, dose delivered and fidelity varied substantially. Third, participation in the intervention was lower than expected, due to intervention- and context-related barriers. Our findings provide an explanation of the effect of the community intervention on primary outcomes, which were improved glucose control and lower incidence of diabetes, in Uganda and South Africa respectively, currently being prepared for publication. In Sweden, the focus was on the feasibility of the intervention hence, the short implementation period of three months was insufficient to evaluate effectiveness.

The three countries had a comprehensive intervention programme but focused their in-depth implementation in accordance with the feasibility and relevance in the context. In Uganda and Sweden, the implementation focused on the peer support intervention whereas in South Africa, it centred around the CC part. The outcome assessment data did not allow comparison in terms of effectiveness of these different components. The community-facility link received the least attention overall in the implementation. The lack of perceived relevance among professional health care workers for this part, especially in South Africa, but to a lesser extent also in Uganda, was found to be a barrier, as was reported in similar studies [21]. A stronger focus on this element could in theory have contributed to more capacity building for the community intervention, and certainly have created a more supportive facility context. Qualitative reports on the contact between peer leaders and facility staff and the modestly positive effects of the intervention in Uganda show the potential for this. 
The context analysis illustrates how context shapes the possibilities of the intervention, and at the same time affects the mechanism of impact. Intervention implementation depended on available resources: in Uganda, the absence of existing community organisations resulted in the establishment of new structures supported by a field coordinator, while in South Africa, the collaboration with an already existing NGO seemed logical. However, the weak managerial context and predefined job descriptions of $\mathrm{CHWs}$ in the latter appeared to be a constraint. Other studies also point to the importance of organizational context and role definition in capacity building [22]. Embedding the intervention in a research project across settings, however, provided the implementation with credibility towards participants for the duration of the project.

The facility context, in which participants received their health care was also assessed. The strengthening of facility-based care in Uganda, especially improved access to medication, changed the context for all participants (intervention and control) and contributed to participant retention and support for the community intervention. The community extension component could potentially have changed the facility context in other countries but this was less visible.

In Uganda and South Africa, the focus was on capacity development of facilitators, which, however, did not increase capacity to the expected levels. The performance of peer support facilitators was variable. In South Africa, project managers reported problems in implementation fidelity, which they linked to a lack of formative work on how CHWs could integrate their newly acquired knowledge on motivational coaching into daily practice. This highlights the importance of absorptive capacity and supportive environment to acquire and operationalise new skills [23].

Monitoring participation reliably was challenging in Uganda and South Africa but seemed relatively low in terms of group attendance and CC support. In Sweden, monitoring of this aspect could more easily be integrated into the largely research team-led activities, revealing that, first of all, mobilization of participants was more difficult than expected. Many potential participants faced a language barrier to understand the Swedish informed consent procedure and, despite the eagerness to be tested, seemed hesitant to join the intervention. Our formative research in this setting suggested that potential participants had mixed perceptions about the potential supportive role of family and friends in the private matter of health and about weak relationships in the community [24]. Evidence from other studies also point to barriers among vulnerable populations, including distrust of research, lack of confidentiality, fear of safety, schedule conflicts, poor access to medical care, lack of knowledge, language and cultural differences [25]. Ongoing analysis show that participants, once having started the intervention, received it very well and quickly built a good rapport with their facilitator [26]. For the peer support intervention, all countries reported that engagement interest levelled off after several sessions. Ongoing analysis of the impact of the intervention on motivational mediators will provide more insights on how well the intervention has induced mechanisms of change at the individual level.

Our findings compare with other studies that report on barriers towards implementation of selfmanagement support interventions involving peer groups and CCs [27]-[29]. Reported success factors of 
peer-support are the right timing of support visits to coincide with patient needs, and the embedding in a broad network of other support services [30]. In SMART2D we presumed the highest need to be present after a new diagnosis for people with T2D, but this was not examined in the situational analysis. The community-facility link could have strengthened this embedding of the intervention, which however proved to be difficult in our study. A recent review of implementation research in LMICs questions the relevance and feasibility of interventions that address individual patient needs and behaviour change in health systems that are not patient-centred [31]. Many included studies reported that organizational cultural or language barriers regarding practice norms made this construct particularly difficult to apply in an LMIC setting. The mediating effect of the context on individual motivation at baseline was described elsewhere [32], [33]. Further analysis will show whether the SMART2D intervention was able to affect individual-level mediators of change.

Strengths of this evaluation are its theoretical basis; frequent interactions between teams of different settings allowing for deep understanding; and a focus on context-specific evaluation needs. We also adapted qualitative methods customized to the context, focusing on the matter of uncertainty in each context. Implementation in this pragmatic trial was a nonlinear process and the process evaluation sheds light on why some aspects of the intervention did not work as expected. The limitations of this study pertain to the completeness of data. Like in many research projects, resources were limited and focused on implementation and not on documentation. This process evaluation focused mostly on the element of the peer support program, limiting its scope. This reduced the potential of the process evaluation to assess, for instance, the fidelity of the $\mathrm{CC}$ intervention, and the mechanism of impact. The reports of implementing agents (peers, CHWs) were not always of consistent quality, which affected the comprehensiveness of the evaluation results. The frequent interactions in the consortium allowed for formal and informal communications which enriched the cross-contextual understanding and the understanding of the findings in the process evaluation.

\section{Conclusions}

Process evaluations are crucial to implementation research. The explicit focus of this process evaluation increased the relevance and utility for the three contexts. Identification of the key uncertainties and conditions facilitates focus, efficient use of resources and context relevant findings. This asks for a flexible design so that additional research questions and tools can be developed to respond to observations and to newly evolving routes during the implementation phase. The overarching framework was instrumental to collect evidence across contexts and to structure reciprocal learning. The frequent interactions including informal exchanges was a rich source of data for the process evaluation and contributed to the deeper understanding of implementation. The findings of this process evaluation point to recommendations for implementation and scale up. When designing an intervention, it is crucial to consider aspects of the implementing organization or structure, absorptive capacity, and to thoroughly assess and discuss implementation feasibility, capacity and organizational context with the implementation team and recipients. 


\section{List Of Abbreviations}

CC Care Companion

CHWs Community Health Workers

FPG Fasting Plasma Glucose

LMICs Low \& Middle Income Countries

MRC Medical Research Council

NCDs Non-Communicable Diseases

NGO Non-Governmental Organisation

SDT Self-Determination theory

SMART2D Self-Management and Reciprocal learning for Type 2 Diabetes'

T2D Type 2 Diabetes

\section{Declarations}

\section{Ethics approval and consent to participate}

In Uganda, approval for the study was obtained from the Research and Ethics Committee of the Makerere University School of Public Health (reference number 426), and from the Uganda National Council for Science and Technology (reference number HS 2118). In South Africa, approval was obtained from the Biomedical Science Research Ethics Committee of the University of the Western Cape (reference number $\mathrm{BM} / 17 / 1 / 36)$. Written informed consent was obtained from eligible subjects before enrolment in the study. Subjects not enrolled in the study but had a fasting plasma glucose test reading of at least 6.1 $\mathrm{mmol} / \mathrm{L}$, and were not already into care were advised to as soon as possible report to the nearest government owned health facility for further evaluation. Local leaders were involved in the design of the SMART2D interventions, and both local leaders and consenting participants participated in the dissemination workshops of findings to policy makers.

\section{Consent for publication}

Not applicable

\section{Availability of data and materials}


Since most of the data used in this paper are either qualitative data or directly related to project management, this data cannot be anonymised and therefore not be made publicly available. Upon reasonable request, the data owner (country $\mathrm{Pl}$, and Karolinska Institute as data owner for the crosscountry data) can decide upon data access. The StaRI checklist [34] for reporting on implementation studies including a checklist on process evaluation items was completed and made available as supplementary material.

\section{Competing interests}

The authors declare that there is no conflict of interest.

\section{Funding}

This study was part of the SMART2D project funded by the European Commission's Horizon2020 Health Coordination Activities (Grant Agreement No 643692) under call "HCO-05-2014: Global Alliance for Chronic Diseases: prevention and treatment of type 2 diabetes". The Uganda site was co-funded by the Sweden International Development Cooperation Agency (Sida) capacity-building grant to Makerere University 2015-2010, Project \#HS 343. The contents of this article are solely the responsibility of the authors and do not reflect the views of the funders of the SMART2D Project.

\section{Author's contributions}

JVO took the lead in the design, analysis and drafting of the paper. PA, DG, JVO, MD and TP conceived and designed the trial. JDM developed the theoretical framework. DG, PD, PA, JVO, KSA, LT, HMA, TP, PDL FXK, GN, MH, RWM and the SMART2D Group implemented the trial. CGO and GT supported the implementation and dissemination in Sweden and in Uganda. All authors participated in writing, and read and approved the final manuscript.

\section{Acknowledgements}

We are grateful to the institutional support of the country site institutions to the SMART2D consortium. The SMART2D consortium includes the following six partner institutions: Makerere University, School of Public Health, Uganda; the University of Western Cape, School of Public Health, South Africa; Karolinska Institutet and Uppsala University, Sweden; Institute of Tropical Medicine, Belgium; and Collaborative Care Systems Finland. We acknowledge the contribution of the other SMART2D Consortium members: David Sanders (RIP), Barbara Kirunda, Anthony Muyingo, Ronald Kusolo, and Edward Ikona. We also acknowledge the study participants for volunteering to participate in the trial, the contribution of the participating health centers and their staff in Uganda and South Africa including The Caring Network Community Health Workers and management, Diabetes SA, Katherine Murphy and Buyelwa Majikela- 
Dlangamanga from the Chronic Disease Initiative for Africa, Tshilidzi Manuga and Sunday Onagbiye and the entire field worker team from South Africa.

\section{References}

1. C. P. Benziger, G. A. Roth, and A. E. Moran, "The Global Burden of Disease Study and the Preventable Burden of NCD," Glob. Heart, vol. 11, no. 4, pp. 393-397, 2016, doi: 10.1016/j.gheart.2016.10.024.

2. J. Kane, M. Landes, C. Carroll, A. Nolen, and S. Sodhi, "A systematic review of primary care models for non-communicable disease interventions in Sub-Saharan Africa," BMC Fam. Pract., vol. 18, no. 1, pp. 1-12, 2017, doi: 10.1186/s12875-017-0613-5.

3. J. Hearn, I. Ssinabulya, J. I. Schwartz, A. R. Akiteng, H. J. Ross, and J. A. Cafazzo, "Self-management of non-communicable diseases in low- And middle-income countries: A scoping review," PLoS One, vol. 14, no. 7, Jun. 2019, doi: 10.1371/journal.pone.0219141.

4. G. F. Moore et al., "Process evaluation of complex interventions: Medical Research Council guidance," Br. Med. J., vol. 350, p. h1258, 2015, doi: 10.1136/bmj.h1258.

5. D. M. Guwatudde D, Absetz P, Alvesson HM, Delobelle P, Ekirapa E, Kiguli J, Mayega RW, Östenson CG, Peterson S, Puoane T, Sanders D, Sundberg CJ, Tomson G, Van Van Olmen J, "Study protocol for the SMART2D adaptive implementation trial: A cluster randomized trial comparing facility only care with integrated facility and community care to improve Type 2 Diabetes outcomes in Uganda, South Africa and Sweden.," BMJ Open, p. 8:e019981, 2018, doi: 10.1136/bmjopen-2017-019981.

6. J. van Olmen et al., "Using a cross-contextual reciprocal learning approach in a multisite implementation research project to improve self-management for type 2 diabetes," BMJ Glob. Heal., vol. 3, no. 6, 2018, doi: 10.1136/bmjgh-2018-001068.

7. P. Absetz et al., "SMART2D-development and contextualization of community strategies to support self-management in prevention and control of type 2 diabetes in Uganda, South Africa, and Sweden," Transl. Behav. Med., vol. 10, pp. 25-34, 2020, doi: 10.1093/tbm/ibz188.

8. J. de Man et al., "Diabetes self-management in three different income settings: Cross-learning of barriers and opportunities," PLoS One, vol. 14, no. 3, p. e0213530, Mar. 2019, doi: 10.1371/journal.pone.0213530.

9. F. Limbani et al., "Process evaluation in the field: global learnings from seven implementation research hypertension projects in low-and middle-income countries," BMC Public Health, vol. 19, no. 1, p. 953, 2019, doi: 10.1186/s12889-019-7261-8.

10. D. Wierenga, L. H. Engbers, P. Van Empelen, S. Duijts, V. H. Hildebrandt, and W. Van Mechelen, “What is actually measured in process evaluations for worksite health promotion programs: A systematic review," BMC Public Health, vol. 13, no. 1, pp. 1-16, Dec. 2013, doi: 10.1186/1471-2458-13-1190.

11. J. van Olmen et al., "Using a cross-contextual reciprocal learning approach in a multisite implementation research project to improve self-management for type 2 diabetes," BMJ Glob. Heal., vol. 3, no. 6, pp. 1-9, 2018, doi: 10.1136/bmjgh-2018-001068. 
12. D. Guwatudde et al., "Study protocol for the SMART2D adaptive implementation trial: A cluster randomised trial comparing facility-only care with integrated facility and community care to improve type 2 diabetes outcomes in Uganda, South Africa and Sweden," BMJ Open, vol. 8, no. 3, pp. 1-12, 2018, doi: 10.1136/bmjopen-2017-019981.

13. R. M. Ryan and E. L. Deci, "The 'What' and 'Why' of Goal Pursuits: Human Needs and the SelfDetermination of Behavior," Psychol. Inq., vol. 11, no. 4, pp. 227-268, 2000, doi: 10.1207/S15327965PLI1104_01.

14. P. Craig, P. Dieppe, S. Macintyre, S. Michie, I. Nazareth, and M. Petticrew, "Developing and evaluating complex interventions: new guidance."

15. E. Proctor et al., "Outcomes for implementation research: Conceptual distinctions, measurement challenges, and research agenda," Adm. Policy Ment. Heal. Ment. Heal. Serv. Res., vol. 38, no. 2, pp. 65-76, 2011, doi: 10.1007/s10488-010-0319-7.

16. R. Mayega, D. Guwatudde, F. Kasujja, G. Naggayi, and A. Muyingo, "Process Evaluation of the SMART2D in Uganda," 2018.

17. L. Timm et al., "Early detection of type 2 diabetes in socioeconomically disadvantaged areas in Stockholm-comparing reach of community and facility-based screening," Glob. Health Action, vol. 13, no. 1, 2020, doi: 10.1080/16549716.2020.1795439.

18. D. Guwatudde et al., "Study protocol of the SMART2D interventions for prevention and management of type 2 diabetes: A pragmatic multi-country cluster randomized trial in Uganda, South Africa and Sweden," BMC Public Health.

19. J. Lindstrom and J. Tuomilehto, "The Diabetes Risk Score. A practical tool to predict type 2 diabetes risk.," Diabetes Care, vol. 26, no. 3, pp. 725-731, 2003.

20. Wikipedia, "Circular migration," 2021. .

21. N. S. Levitt et al., "Referral outcomes of individuals identified at high risk of cardiovascular disease by community health workers in Bangladesh, Guatemala, Mexico, and South Africa," Glob. Health Action, vol. 8, no. 1, 2015, doi: 10.3402/gha.v8.26318.

22. N. Ibrahim et al., "A systematic review of influences on implementation of peer support work for adults with mental health problems," Soc. Psychiatry Psychiatr. Epidemiol., vol. 55, no. 3, pp. 285293, Mar. 2020, doi: 10.1007/s00127-019-01739-1.

23. N. D. Ritchie, "Solving the puzzle to lasting impact of the national diabetes prevention program," Diabetes Care, vol. 43, no. 9, pp. 1994-1996, 2020, doi: 10.2337/dci20-0031.

24. J. de Man et al., "Diabetes self-management in three different income settings: Cross-learning of barriers and opportunities," PLoS One, vol. 14, no. 3, p. e0213530, Mar. 2019, doi: 10.1371/journal.pone.0213530.

25. S. J. UyBico, S. Pavel, and C. P. Gross, "Recruiting vulnerable populations into research: A systematic review of recruitment interventions," J. Gen. Intern. Med., vol. 22, no. 6, pp. 852-863, 2007, doi: 10.1007/s11606-007-0126-3. 
26. L. Timm et al., "Application of the Theoretical Framework of Acceptability to assess a telephonefacilitated health coaching intervention for the prevention and management of type 2 diabetes.," (submitted), 2021.

27. M. Heisler, "Overview of peer support models to improve diabetes self-management and clinical outcomes," Diabetes Spectr., vol. 20, no. 4, pp. 214-221, 2007, doi: 10.2337/diaspect.20.4.214.

28. T. S. Tang, G. X. Ayala, A. Cherrington, and G. Rana, "A review of volunteer-based peer support interventions in diabetes," Diabetes Spectr., vol. 24, no. 2, pp. 85-98, 2011, doi: 10.2337/diaspect.24.2.85.

29. E. B. Fisher et al., "Peer Support For Self-Management Of Diabetes Improved Outcomes In International Settings," Health Aff., vol. 1, pp. 130-139, 2012.

30. J. Dunn, S. K. Steginga, S. Occhipinti, and K. Wilson, "Evaluation of a peer support program for women with breast cancer - Lessons for practitioners," J. Community Appl. Soc. Psychol., vol. 9, no. 1, pp. 13-22, 1999, doi: 10.1002/(SICI)1099-1298(199901/02)9:1<13::AID-CASP488>3.0.C0;2-F.

31. A. R. Means et al., "Evaluating and optimizing the consolidated framework for implementation research (CFIR) for use in low- And middle-income countries: A systematic review," Implement. Sci., vol. 15 , no. 1, pp. 1-19, 2020, doi: 10.1186/s13012-020-0977-0.

32. J. De Man et al., "Testing a Self-Determination Theory Model of Healthy Eating in a South African Township," Front. Psychol., vol. 11, p. 2181, Aug. 2020, doi: 10.3389/fpsyg.2020.02181.

33. J. de Man et al., "What motivates people with (pre)diabetes to move? Testing self-determination theory in rural Uganda," Front. Psychol., vol. 11, no. March, pp. 1-11, 2020, doi: 10.3389/fpsyg.2020.00404.

34. H. Pinnock et al., "Standards for Reporting Implementation Studies (StaRI) Statement," BMJ, vol. 356, no. March, pp. 1-9, 2017, doi: 10.1136/bmj.i6795.

\section{Figures}




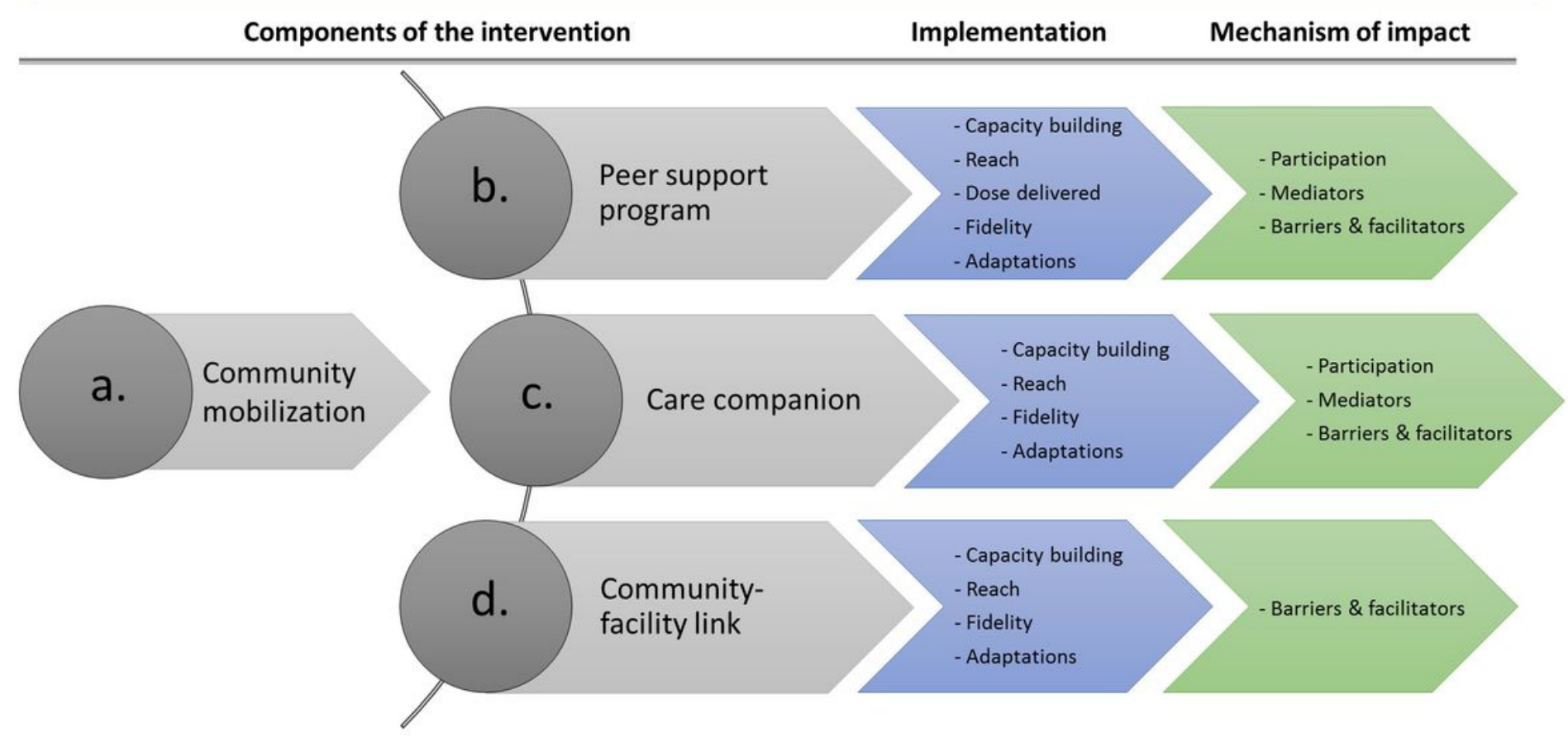

\section{Figure 1}

SMART2D process evaluation framework.

\section{Supplementary Files}

This is a list of supplementary files associated with this preprint. Click to download.

- StaRIOImenSMART2Dprocessevaluation.docx 